Manuscript ID: ac-2016-00544w

Supporting Information for Publication

Using Mass Spectrometry to Quantify Rituximab and Perform Individualized Immunoglobulin Phenotyping in ANCA-associated Vasculitis

John R. Mills ${ }^{1}$, Divi Cornec ${ }^{2,3}$, Surendra Dasari ${ }^{4}$, Paula M. Ladwig ${ }^{1}$, Amber M. Hummel $^{2}$, Melissa Cheu ${ }^{5}$, David L. Murray ${ }^{1}$, Maria A. Willrich ${ }^{1}$, Melissa R. Snyder ${ }^{1}$, Gary S. Hoffman ${ }^{6}$, Cees G.M. Kallenberg ${ }^{7}$, Carol A. Langford ${ }^{6}$, Peter A. Merkel ${ }^{8}$, Paul A. Monach ${ }^{9}$, Philip Seo ${ }^{10}$, Robert F. Spiera ${ }^{11}$, E. William St. Clair ${ }^{12}$, John H. Stone $^{13}$, Ulrich Specks ${ }^{2}$, ${ }^{*}$ David R. Barnidge ${ }^{1}$

${ }^{1}$ Department of Laboratory Medicine and Pathology, Mayo Clinic Rochester, MN, 55905

${ }^{2}$ Division of Pulmonary and Critical Care Medicine, Mayo Clinic Rochester, MN, 55905

${ }^{3}$ Rheumatology Department, Brest University Hospital, 29609 Brest, Cedex, France

${ }^{4}$ Department of Health Sciences Research, Mayo Clinic Rochester, MN, 55905

${ }^{5}$ Genentech Inc., South San Francisco, CA, 94080

${ }^{6}$ Cleveland Clinic Foundation, Cleveland, $\mathrm{OH}, 44195$

${ }^{7}$ University of Groningen, $9712 \mathrm{CP}$ Groningen, the Netherlands,

${ }^{8}$ University of Pennsylvania, Philadelphia, PA, 19104

${ }^{9}$ Boston University Medical Center, Boston, MA, 02115

${ }^{10}$ Johns Hopkins University, Baltimore, MD, 21218

${ }^{11}$ Hospital for Special Surgery, New York, NY, 10021

${ }^{12}$ Duke University, Durham, NC, 27710

${ }^{13}$ Massachusetts General Hospital, Boston, MA, 02114

*Corresponding Author:

Dr. David R. Barnidge

Mayo Clinic

$2001^{\text {st }}$ St SW

Rochester, MN 55905

Phone: (507) 266-4777

Email: barnidge.david@mayo.edu

Table of Contents Supporting Information

Cover page - S1

Table S1 - page S2

Table S2 - page S3

Figure $\mathrm{S} 1$ - page $\mathrm{S} 4$ 
Figure S2 - page S5

\begin{tabular}{|l|l|l|l|l|l|}
\hline Table S1 & Rituximab & \multicolumn{2}{|l|}{ Standards } & & \\
\hline Plate & Blank & $\mathbf{1 0} \mathbf{u g} / \mathbf{m L}$ & $\mathbf{5 0} \mathbf{~ u g} / \mathbf{m L}$ & $\mathbf{1 0 0} \mathbf{u g} / \mathbf{m L}$ & $\mathbf{2 0 0} \mathbf{~ u g} / \mathbf{m L}$ \\
\hline $\mathbf{1}$ & 10.4 & 12 & 44 & 104 & 250 \\
\hline $\mathbf{2}$ & 6.4 & 19 & 48 & 88 & 254 \\
\hline $\mathbf{3}$ & 4.2 & 20 & 51 & 83 & 256 \\
\hline $\mathbf{4}$ & 3.8 & 16 & 50 & 91 & 254 \\
\hline $\mathbf{5}$ & 12 & 19 & 41 & 97 & 252 \\
\hline $\mathbf{6}$ & 8.2 & 19 & 47 & 88 & 254 \\
\hline $\mathbf{7}$ & 4.3 & 12 & 46 & 106 & 250 \\
\hline $\mathbf{8}$ & 5.0 & 12 & 52 & 97 & 252 \\
\hline $\mathbf{9}$ & 6.5 & 18 & 46 & 93 & 253 \\
\hline $\mathbf{1 0}$ & 7.8 & 18 & 46 & 93 & 254 \\
\hline AVE & $\mathbf{6 . 9}$ & $\mathbf{1 6}$ & $\mathbf{4 7}$ & $\mathbf{9 4}$ & $\mathbf{2 5 3}$ \\
\hline \%CV & $\mathbf{4 1}$ & $\mathbf{1 9}$ & $\mathbf{6 . 6}$ & $\mathbf{7 . 6}$ & $\mathbf{0 . 8}$ \\
\hline Tab & & & & & \\
\hline
\end{tabular}

Table S1 Legend.

The back-calculated concentrations of each rituximab pooled normal serum standard determined using the standard curve run for the corresponding plate. Plates contained standards, QC, and patient samples and were prepared and run over a period of 6 weeks. 


\begin{tabular}{|l|l|l|l|}
\hline Table S2 & Rituximab & Concentrations & in ug/mL \\
\hline $\begin{array}{l}\text { Collection } \\
\text { Wate }\end{array}$ & miRAMM & ELISA & p-value \\
(n=94) & $134 \pm 5$ & $113 \pm 4$ & $<0.01$ \\
\hline $\begin{array}{l}\text { Week 4 } \\
\text { (n=91) }\end{array}$ & $220 \pm 9$ & $177 \pm 7$ & $<0.01$ \\
\hline $\begin{array}{l}\text { Month 2 } \\
\text { (n=88) }\end{array}$ & $70 \pm 3$ & $64 \pm 3$ & 0.02 \\
\hline $\begin{array}{l}\text { Month 4 } \\
\text { (n=59) }\end{array}$ & $22 \pm 1$ & $18 \pm 2$ & $<0.01$ \\
\hline $\begin{array}{l}\text { Month 6 } \\
\text { (n=29) }\end{array}$ & $17 \pm 1$ & $14 \pm 6$ & 0.55 \\
\hline
\end{tabular}

Table S2 Legend.

Mean concentration \pm the standard error of the mean of rituximab in patient samples at different time points as determined by miRAMM and ELISA. Also shown is the $p$-value associated with each set of means at the different time points. 


\section{Figure S1}

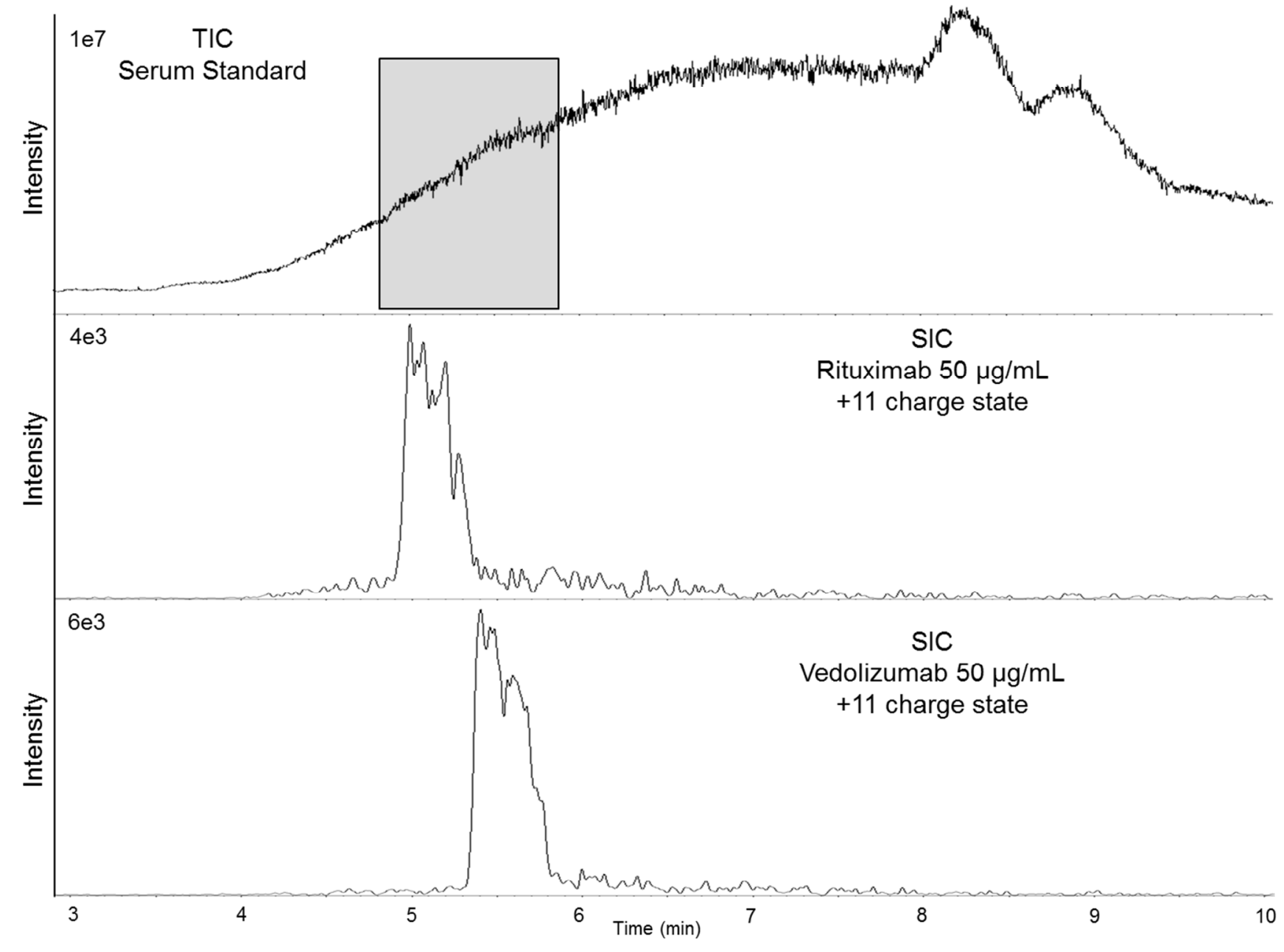

Figure S1 Legend. Total ion chromatogram (TIC - top of figure) along with selected ion chromatograms (SIC) for a $50 \mu \mathrm{g} / \mathrm{mL}$ standard of rituximab analyzed by miRAMM. The $\mathrm{TIC}$ represents the signal for all the ions detected in the mass spectrometer over the $600-2,500 \mathrm{Da} \mathrm{m} / \mathrm{z}$ scan range. The SIC in the middle of the figure displays the response for the +11 charge state $(m / z=2,094.95 \pm 0.5 \mathrm{Da})$ of the rituximab light chain at as it elutes off the column while the SIC on the bottom of the figure displays the response for the +11 charge state $(\mathrm{m} / \mathrm{z}=2,173.82 \pm 0.5 \mathrm{Da})$ of the vedolizumab light chain. The 5-6 minute retention time window highlighted in gray is the TIC was used to generate the summed mass spectra used for determining peak areas for quantitative analysis. 


\section{Figure S2}
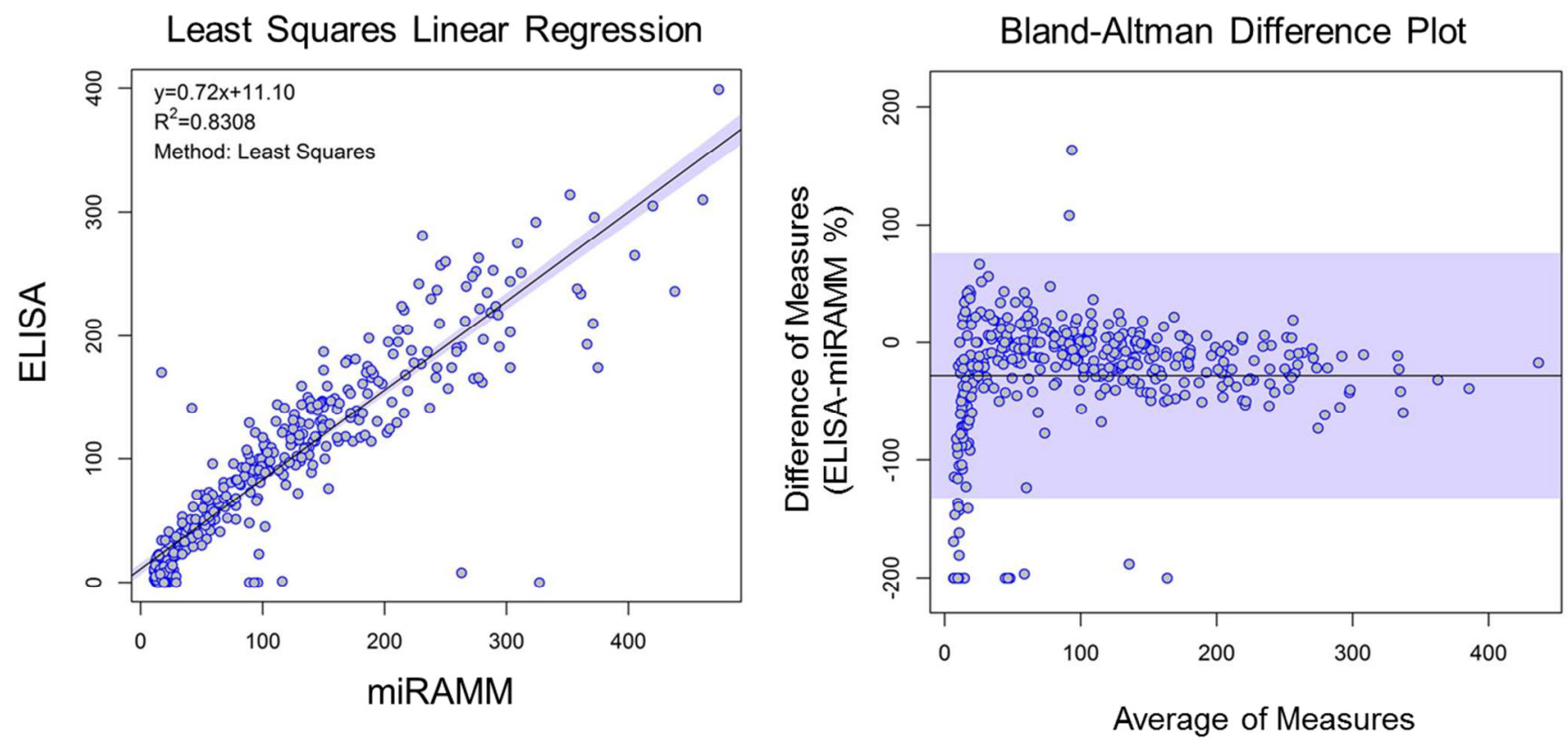

Figure S2 Legend.

Least squares linear regression analysis (left) and Bland-Altman plot (right) for $n=411$ patient samples comparing the concentration of rituximab in $\mu \mathrm{g} / \mathrm{mL}$ determined by miRAMM and ELISA. All miRAMM samples had rituximab concentrations $\geq 9.7 \mu \mathrm{g} / \mathrm{mL}$ the LLOQ. 